
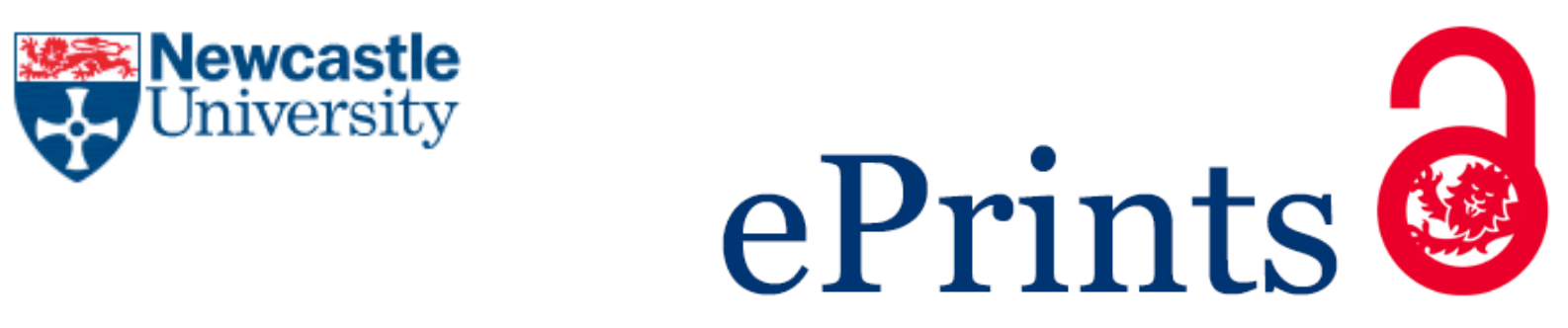

Mitra S, Kulkarni S, Stanfield J.

Learning at the Edge of Chaos: Self-Organising Systems in Education.

In: Lees, HE; Noddings, N, ed. The Palgrave International Handbook of

Alternative Education. London, UK: Palgrave Macmillan, 2016, pp.227-239.

\title{
Copyright:
}

This extract is taken from the author's original manuscript and has not been edited. The definitive, published, version of record is available here: http://www.palgrave.com/us/book/9781137412904 for product on www.palgrave.com and www.palgraveconnect.com. Please be aware that if third party material (e.g. extracts, figures, tables from other sources) forms part of the material you wish to archive you will need additional clearance from the appropriate rights holders.

Date deposited:

$13 / 10 / 2016$

Embargo release date:

19 September 2019 


\section{Learning at the edge of chaos - self-organising systems in education}

Abstract: This chapter takes stock of the evolution of the current primary education model and the potential afforded by current technology and its effects on children. It reports the results of experiments with self-organising systems in primary education and introduces the concept of a SelfOrganised Learning Environment (SOLEs). It then describes how SOLEs operate and discusses the implications of the physics of complex systems and their possible connection with self-organised learning amongst children. The implications for certification and qualifications in an internetimmersive world are also discussed.

Key words: SOLE, self-organised learning environments, edge of chaos

\section{Authors:}

Sugata Mitra is Professor of Educational Technology and Director of SOLE Central at Newcastle University. His "Hole in the Wall" experiments, begun in 1999, revealed that groups of children can learn almost anything by themselves given Internet access and the ability to work collaboratively. He developed this original idea into the SOLE approach, reaching out to children with minimal or no educational opportunities, in remote corners of the globe. He has driven research into making this approach part of mainstream education. At TED2013, Sugata Mitra made a bold TED Prize wish: to revolutionize the future of learning.

Dr Suneeta Kulkarni is Research Director for The School in the Cloud TED Prize project. With a background in Child Development, she has been working with Self Organised Learning Environments, primarily in disadvantaged locations. She provides support, counsel and guidance to collaborating organizations that wish to establish SOLEs. She facilitates the Granny Cloud Team which she has led since its beginning in 2008. She works with the Grannies to bring self-organised learning to children all over the world. She is based in Pune, India. 
Dr James Stanfield is a Lecturer in Education at SOLE Central, Newcastle University and has been working on the School in the Cloud TED Prize Project for the last 12 months. He is currently responsible for the development of the School in the Cloud web platform (www.theschoolinthecloud.org), which involves developing strategic partnerships, liaising with and taking input from project stakeholders, making recommendations for the strategic direction of the platform, defining and communicating platform objectives and working with the project team to prioritise developments. 


\section{Learning at the edge of chaos - self-organising systems in education}

Education and educational goals have changed over time in response to different political ideologies, the changing needs of society and the availability of new resources and technology. Yet this response, particularly in the past few decades, has lagged far behind the possibilities afforded by technology and is out of sync with the world beyond traditional school walls. The need to develop new and more responsive models of education is now urgent.

\section{Historical perspective}

The introduction of reading and writing with the advent of paper and subsequently the printing press changed the emphasis of primary education from listening and reciting to good spelling, handwriting and reading comprehension. The introduction of the decimal system brought numeracy to the very young. As more technology emerged, around the early 19th century, the real-world technology that was used for solving technical problems such as rulers, compasses, dividers, protractors, paper, pens, and later, logarithm tables and slide rules were also introduced into the examination hall. In other words, the learner was expected to prove that he or she was capable of solving real-world problems the way they are solved in the real world. The teachers, in order to cope with this system of examination, would encourage learners to use all these technologies. During the Industrial Revolution, knitting, sewing, kitchen automation, and a host of new technologies entered the primary school. As writing supplanted the oral tradition, the emphasis shifted to "taking notes properly" as an important skill, rather than memorising. Later, the introduction of logarithm tables into the classroom and examinations would change the emphasis from multiplying by hand and memorising tables to correctly and quickly using log tables.

During the eighteenth and nineteenth centuries the world was mostly divided into empires. In order to administer a colonised world, the empires invented modern systems of administration and management, essentially systems of data processing, using people as the computing elements. Data was processed by clerks and transmitted physically on paper, using ships as the main form of 
transportation. Communication was through a chain of command, invented earlier by the military. In order to produce the large number of clerks needed to administer empires, primary schooling had to adopt a factory model, aimed at producing identical and interchangeable clerks. The skills most needed by clerks and other officials in the chain of command were reading, writing, and arithmetic. These became the three pillars of primary education and so they remain, centuries after the empires have ended.

The military-industrial-administrative machines of the Age of Empires also needed strict rules of dress, behaviour and conduct. These were introduced into primary education through religion and martial discipline. Learners were taught not to ask questions, but to obey orders and norms laid out by the society they lived in. This also continues today. In the meantime, technologies and new discoveries from the older civilisations and empires such as gunpowder and tea from China, opium and mathematics from India, architecture from Greece and the Middle East, tobacco, potatoes, and chillies from the New World; all went into the creation of an industrial and technological revolution in Europe. Schools became the producers of not only clerks but also accountants and factory workers. During that era, the average school rarely needed to make significant changes to its curriculum, perhaps once in fifty years, and the process of changing curriculum, examination systems, and teaching methods was geared to that pace of change. The process remains slow today. Just as guns changed an age, two inventions were to change the age of empires: the telephone and the digital computer. In the second half of the twentieth century, computers had begun to replace the clerks at the lowest layers of the military-industrial-administrative machine, while the telephone was shortening chains of command. Schools struggled to cope with these changes. Computerassisted education, computer-aided learning, programmed instruction, and computer-based teaching were all attempts to replace teachers with machines that would, people hoped, close the gap between the rich and the poor. These attempts were doomed to fail because they assumed that learning required a teacher, a classroom of 36 square metres, 30 children, and classes lasting one 
hour: a model inherited from the oral tradition of 5,000 years ago. Curricula around the world remained fairly static: they assumed a top-down, hierarchical, predictable and controllable world that progresses slowly. There was still no reason to believe otherwise.

Three quiet revolutions in science during the first half of the 20th century, were revealing something vastly different about the way things work: information and disorder are related (Shannon 1948); the act of observation changes the observable (Heisenberg 1927); and connected things show emergent properties not expected from them (Huxley and Huxley 1947, p. 20). The world of physics changed in the twentieth century, from a model that was ordered, well understood and controllable, to one that was chaotic and probabilistic. However the lack of responsiveness to these insights lies at the base of many ills of the current educational system. We are still struggling to understand a universe that is governed by probability, chaos and emergence. Schools and the children they continue to produce know little of this. The clerks and their managers remain in a state of denial; still hiding in a mythical orderly world, where things happen by design.

A key change that shook this predictable certainty and began forcing society out of denial mode was that towards the end of the twentieth century, computers began to connect to each other over telephone lines. By the year 2000, millions of them were connected; by 2010, it was billions. Connected by wireless, electromagnetic signals, the biggest network of information-exchanging entities, the internet, was passing more bits of information back and forth than there are stars in the universe. From that cloud of chaotic interconnection order (in the form of the internet) has emerged.

\section{Children and the internet}

Since 1999, a number of experiments have been building up to a pedagogical method that is considerably different from the traditional methods used in schools in the last century. In one of the first of these experiments, often referred to as the "Hole in the Wall", computers, connected to the internet, were embedded into walls in villages and urban slums in India. They were much like the 
automatic teller machines used by banks, but their screens were larger and placed at a height that made it convenient for children aged eight to thirteen to use them. These computers had no specific learning software and children were given no instructions about what they were and what they were for, except for a sign that said they were for free use by children. In 1999, poor children in India often did not know what a computer was and were quite unaware of the internet. In a study that lasted over 5 years, Mitra and his colleagues (Mitra et al. 2005) found that children could learn to use the computers to play games, download media, and search for information, among other things. Moreover, the computers were placed in locations where local adults knew nothing about how to use them, and installations designed so they were nearly impossible for adults to use. Using a sample of children in seventeen locations across India and various tests, we concluded that the children had learned to use the computers by themselves. Today, of course, this is not at all surprising. It is also important to note that these "Hole in the Wall" computers remained in working condition for only about two years after the experimental period, as no funding was available to maintain them after that. But during this period the experiments indicated that children (usually aged 8-13), given access to the internet and left unsupervised, demonstrated education achievements.

It is also important to note that to reach these educational objectives, the children invariably worked in groups, interacting constantly with each other, in a somewhat chaotic way. Their approach scarcely resembled the orderly learning environment provided by a school classroom. Our observations led us to suspect that their learning was the outcome of a self-organising system, in much the same way it is understood in the physical sciences or mathematics: a set of interconnected parts, each unpredictable, producing spontaneous order in an apparently chaotic situation.

From the experiments carried out between 1999 and 2005, the following findings were documented. Firstly, children can learn to use computers and the internet by themselves, irrespective of who or where they are and what language they speak (DeBoer 2009; Mitra et al. 2005). Secondly, children 
can achieve educational objectives by themselves, related to: standard school examinations in computer science and mathematics (Inamdar and Kulkarni 2007); improvement in their English pronunciation (Mitra, Tooley, Inamdar, and Dixon 2003); and improve their school achievement (Dangwal, Sharma, and Hazarika 2014; Dangwal and Thounaojam 2011). Thirdly, children showed self-organising behaviour that resulted in learning in "minimally invasive" environments (Dangwal and Kapur 2008, 2009a, b), and finally, children appeared to understand content that was years ahead of that expected for their age group (Inamdar 2004; Mitra 2012).

A related study by Mitra, Dangwal, and Thadani (2008) showed that children in remote areas perform less well in school, usually because of the quality of instruction they receive, as good teachers tend to migrate away from remote areas. An alternative method, suggested by the findings above, might help reduce this problem of performance. This was tried out in an experiment to seek the limits to such self-organised learning. Mitra and Dangwal (2010) found that groups of Tamilspeaking children in a southern Indian village were able to understand the basic concepts of biotechnology on their own, in English. This surprising result seemed to indicate that children, when working in groups, were able to reach levels of learning years ahead of standard expectations. However, they understood considerably less than did a control group who were taught the same subject. We then introduced an affectionate and admiring, but not necessarily knowledgeable, adult, and found that she was able to equalise the levels of learning between the control and experimental groups. This friendly, non-threatening adult presence described as the "grandmother's method" stand behind, admire, act fascinated and praise - became the basis for organizing remote mediation by connecting volunteers (many of whom were retired teachers) to children using peer-to-peer video communication such as Skype. This formation is today better known as the 'Granny Cloud' (Kulkarni, S. \& Mitra, S. 2010).

\section{Self-Organised Learning Environments (SOLEs)}


The insights from these results, lend themselves to a case for creating unsupervised learning environments for children, as an alternative learning method or approach. We call these SelfOrganised Learning Environments (SOLES). A SOLE inside a school or any indoor environment attempts to simulate the environment of the outdoor "Hole in the Wall" design. This can be created by having computers with group seating arrangements so that a group of children can easily share a computer and by ensuring that the number of children in the space is 4 or 5 times that of the number of computers. For each session, the teacher, facilitator or mediator will provide the class with a big and challenging question. This would ideally be a question that the children would find extremely difficult or impossible to answer if they were sat by themselves in a traditional classroom with no access to the internet. The children are then invited to form their own groups around each computer. Given the ratio of children to computers, this happens naturally. Children are allowed to change groups, talk to one another, talk to other groups, and walk around looking at others' work. Towards the end of the session each group is then asked to present their findings to the rest of the class. Communication and collaboration are therefore key features of a SOLE.

While this approach clearly builds upon the benefits associated with numerous other approaches including collaborative learning, peer learning, project based learning and enquiry based learning, two distinctive features can be identified. Firstly, the internet plays a fundamental role. Viewed as a spontaneously emerging global brain, its potential to transform learning as we know is enormous. Secondly, as a result of the above, the teacher's role in a SOLE changes and becomes minimal. While teachers are responsible for introducing the big question and observing the children they are not expected to intervene in the learning process. Instead they are expected to adopt the "grandmother's method". This factor could be critical to the success of a SOLE. The fact that many teachers in conventional settings find it difficult to relinquish control is a challenge that still needs to be addressed. More comparative studies are therefore needed to examine data from locations where it appears to work and where it clearly doesn't. However, when all of this goes as planned, the result is the mildly chaotic situation of the "hole in the wall" experiment. 
SOLEs can be used in several different contexts including regular classrooms, community centres, specially designed labs, or home-schooling situations. In a SOLE large screens are preferred as these help small groups to collaborate. The use of highly visible large screens also appears to discourage children from visiting unrelated websites. The dynamics of working in a group also appears to have a similar effect. SOLEs should also, preferably, be conducted in enclosures with transparent walls. However, since specially constructed spaces may not always be feasible, the design has to allow for easy screen visibility to people both inside and outside of the room. How a SOLE space is designed will have a significant impact on how it operates and ideally the children who are going to use the SOLE should be involved in the initial design of space itself.

At times, the SOLEs can also be used for connecting children in developing countries to 'Granny' eMediators from different countries around the world. When children do it as intended, this kind of work can have a strong and positive impact on cultural development and English and/or other language fluency. This approach is particularly useful in areas where teachers cannot or will not go. To date this approach has involved a Granny appearing on a single static computer screen, or a larger screen fixed to a classroom wall, and then interacting with a small number of children. However, more recently trials have taken place using mobile (robot like) screens, which enable the Granny to move within the SOLE (via remote control) and interact with a larger number of children. Initial feedback suggests that both Grannies and children find this technology more engaging as the Granny clearly has much more of a physical presence within the SOLE.

Self-organised learning activity, like the types discussed here, is not yet clearly understood. Reading comprehension is obviously very important to the process. Moreover, when children search the internet for information, most of what they encounter was written with adults in mind. This means that, if they are to apply effective search and analysis skills, children need to be able to read at adult comprehension levels. At first, this would appear to be a showstopper. However, actual experience with SOLEs, suggests that many children seem to be able to make sense of material at reading levels 
considerably above their own. This anomalous result is intriguing and may well be the key to understanding this form of learning.

We have observed that the SOLE method does not operate well with what one might think of as easy questions or easy-to-read materials. By "easy", we mean questions or material currently considered suitable for the age levels of the learner group. Children working in groups engage more deeply when confronted with questions and material well above their expected competency level. They seem to enjoy doing such tasks. We conjecture that children who perceive a task as one they are confident about doing individually would rather work alone in order to get individual credit. On the other hand, if they perceive a task as difficult or impossible, they would rather work in groups, possibly to increase their chances of succeeding and to reduce any potential discredit for getting things wrong. The 'curiosity or interest quotient' may well be a factor increasing the likelihood of children taking it on. This conjectures needs to be tested under controlled conditions.

As one might expect, many of these initial findings have raised further challenging questions. For example, could a conventional classroom, because of its very design, set itself up for 'failure' unless the teacher/facilitator has understood the approach? If this is the case could community centres with minimal resources provide more robust SOLE settings? What will be the level of achievement in curricular topics in these different contexts and how will this achievement be measured? How will examination systems need to change so that they encourage this approach? And while we lobby for much needed change in both examination and reporting systems how do we encourage/adapt the SOLEs for use in traditional school settings? How could this approach be extended to learning at higher education levels? Having acquired a given set of skills, and needing to acquire new ones fairly frequently in a fast changing world, how could the SOLE approach be used as part of continuing education? Finally, what kind of outside classroom usage or adapted usage could be conceived? This would need a consideration of community centres and their special relevance in disadvantaged areas where 'good' schools/teachers are absent and also home schooling in the context of gradually 
increasing numbers of parents opting out of the existing, rigid educational system. As we gain in our understanding of how SOLEs work, it will be easier to ensure that this approach can be used more and more effectively in different contexts.

\section{Schools in the Cloud}

The work described above was carried out from 2007 to 2013 in schools around the world in collaboration with schools that were interested in understanding how SOLEs work. However, these were traditional schools and the work was done as a one-off demonstration of a possible new method of learning. The schools involved were located in Argentina, Australia, Chile, China, England, India, Italy, the United States, Uruguay, and several other countries. Many teachers retained their regular methods, many modified the SOLEs to suit their curricular purposes and many did not continue with the new approach.

Examining these questions and verifying these results became possible following the award of the TED Prize in February 2013. This phase of the work and the potential of SOLEs as a viable alternative education strategy is now being studied through seven specially created facilities where groups of children can work with the internet with minimal teacher intervention. Each of these will also include interactions with 'Granny' eMediators who can interact with children via Skype. Also on the anvil are experiments with conducting full-fledged SOLE sessions over skype through the eMediators.

These facilities, called Schools in the Cloud, have been constructed in five locations across India and two in schools with excellent facilities in the North East of England. They are located in places where we can observe their functionality and impact, if any, on children's learning and development over a large range of socioeconomic and cultural environments over the next couple of years. Comparisons will be made between each of the seven locations and also between the facilities in India and those in the UK. While it is too early to report on any findings it has been fascinating to watch these new facilities emerge and develop. Observing these initial developments has also helped to shed light on 
some of the complexities involved in this research and the folly of attempting to find a one size fits all solution. Yet, preliminary observations indicate that children find SOLE sessions led by Big Questions much more engaging that a traditional lesson led by the teacher. In the Indian locations 'Granny sessions' also touch a chord in children and parents alike. This is in keeping with neuroscience research that emphasizes the importance of the early years for such warm interactions (Winter, 2010). Additionally, studies that have examined the sensitive periods with reference to second language acquisition indicate that 'native-like proficiencies' are unlikely to develop in the second language unless this is acquired by mid-childhood (Thomas \& Johnson, 2008).

As the project develops it has become increasingly clear that for these facilities to operate effectively, curricula, pedagogy, and examinations will all need to be changed. For example, curricula will need to be generalised to avoid referring to specific topics. The Common Core initiative in the United States (CCSSI 2014) is an example of an attempt to do so. Curricula of this kind are more amenable to SOLE methodology and can be triggered by activities suggested remotely. Changes in curriculum and pedagogy can be achieved with least effort by changing the examination system. Alternatively, introducing the assistive technology of our times (and that implies computers connected to the internet) into the examination system can also lead to a change in the nature of questions in an examination.

Take, for example, the following question which is typical of a GCSE examination question in the UK: Greenhouse gases keep the Earth warm because...

- They are good insulators.

- They trap energy as it enters the Earth's atmosphere from the Sun.

- They allow more radiation to pass through.

- They re-radiate energy back to the Earth. 
Anyone with access to the internet should be able to answer this question in a short period of time. Now, consider what would happen if the question was changed to:

- What causes global warming and can it be prevented?

Clearly a question like this would not only check the examinee's abilities to address complex issues and 'higher order thinking' rather than questions focusing on specific information, but would also promote his or her learning. Using the internet to examine has the potential to combine curriculum, pedagogy, and testing into a single activity very much in keeping with the idea that assessment should be integral and ongoing. Introducing such changes into schooling would require considerable changes in education policy. Adapting the SOLEs for use in traditional classrooms could pave the way for much needed changes in both curricula and the examination system.

A policy-making body prepared to take up this challenge would need to take into account the fact that individual performance does not necessarily indicate the efficiency of an education system. Furthermore, it is no longer necessary for learners to "know" everything. Instead they should be able to find out what and how to know, effectively and in the shortest possible time. Thirdly, creativity and imagination are more important than "order and method" and where possible they should be documented or measured as important indicators of the efficiency of the education system. Finally, while suggesting the use of 'Big Questions", there needs to be a recognition of the fragility of the method unless the questions posed are genuinely challenging and thought provoking.

\section{Learning and chaos}

The way in which children behave during SOLE sessions around the world are reminiscent of selforganising systems. Something is said to be self-organised if, when left to itself, it tends to become more organized. This is an unusual property as we often expect 'things' that are left to themselves to become more disorganised and chaotic. Furthermore, when we observe order or well organised structures in society we are often tempted to think that an external body or organisation is 
responsible for making this happen. However, we now know that this is not the case and complexity theory has helped us to better understand how social orders, such as language, spontaneously emerge and evolve themselves over a long period of time. The suggestion that education could be a spontaneous order would have significant implications for the research community. For example, in a complex and chaotic world, similar conditions could produce very different outcomes. Therefore, if something works once, there would be no guarantee that it will work the same again a second time. Regularity and conformity therefore break down to irregularity and diversity and effects are no longer the straightforward and continuous functions of causes. Furthermore, universal theories now provide inadequate accounts of local developments and it is these emerging local rules and behaviours that undermine our ability to generalise about "what works".

Self-organising systems fall under the general area of chaos theory in physics. The definition of chaos can be applied to education in general "A system whose long-term behaviour is unpredictable: tiny changes in the accuracy of the starting value rapidly diverge to anywhere in its possible state space. There can, however, be a finite number of available states, so statistical prediction can still be useful"' (CSG 2007).

The sentence above may well sum up, in the language of physics, what we understand as education and assessment. Working with a group of children, a school cannot predict what will emerge at the end of schooling, but can make statistical predictions based on test scores. In a SOLE, children seem to create and maximise meaning out of the information content of what they are researching. This, too, is uncannily close to the definition of the term "Edge of Chaos': the tendency of dynamic systems to self-organise to a state roughly midway between globally static (unchanging) and chaotic (random) states. This can also be regarded as the liquid phase, halfway between solid (static) and gas (random) natural states. In information theory, this is the state containing the maximum information" (CSG 2007). 
Finally, we believe the science of emergence offers a potential explanation of children's ability to read in groups above their individual capabilities. Emergence, a common phenomenon in nature, is the appearance of properties that are not evident in the parts of a system. Nebulas, flowers, cells, and markets all show emergent behaviour. Again, CSG (2007) provides a definition: "System properties that are not evident from those of the parts. A higher-level phenomenon that cannot be reduced to that of the simpler constituents and needs new concepts to be introduced". It continues, "This property is neither simply an aggregate one, nor epiphenomenal, but often exhibits 'downward causation'. Modelling emergent dynamical hierarchies is central to future complexity research".

\section{Consequences: A speculative discussion}

Urban children, and increasingly those in other settings, are accessing the internet through a host of devices that are all getting cheaper, lighter and smaller. It is entirely possible to imagine a situation in the near future where it would not be possible to detect whether or not a person was consulting the internet. What will happen to examinations when the internet is available to the examinee? It is also imaginable that, using the internet, a learner could "pretend" to be educated. By "pretend", we mean the learner could claim to know a subject that he or she has not been taught in the traditional sense. When children use SOLEs, in a sense they are doing just that. However, we must notice that the act of "pretending" eventually results in their learning the subject. In other words, when a learner practices a set of skills without being taught them but uses the internet for support, she learns the subject, over a period of time. The learner becomes what she pretends to be.

Let us imagine a person claiming to be an accountant, who has no knowledge of the subject. Using the Internet, he solves accounting problems for his clients. He uses search engines, websites, and web-based tools and also consults people on the Internet through voice, video or text. In the first instance, he may look up the words "balance sheet". The next time, he would not look up those words because he would know what they mean. The Internet makes it possible for people to 
become self-made professionals, just as in another age people became self-made mechanics, electricians, etc.

What would happen to certification and qualifications in an internet-immersive world? What would curriculum mean when learners have access to the latest in the field within minutes after it is published or spoken about? These questions challenge the fundamentals of traditional education: a system that has its origins in the colonial and industrial ages and whose purpose, by and large, is to produce similar people. That purpose itself is now obsolete and so, perhaps, is the system. SOLEs are a first faltering step towards preparing our children for a future we can barely imagine.

\section{References}

CALResCo [Complexity \& Artificial Life Research Concept] (2007). Complex systems glossary. New Mills: CALResCo.

CCSSI [Common Core State Standards Initiative] (2014). English language arts standards, history/social studies, grade $6-8$. CCSSI.

Dangwal, R., \& Kapur, P. (2008). Children's learning processes using unsupervised "hole in the wall" computers in shared public spaces. Australasian Journal of Educational Technology, 24(3), 339-354.

Dangwal, R., \& Kapur, P. (2009a). Learning through teaching: Peer-mediated instruction in minimally invasive education. British Journal of Educational Technology, 40(1), 5-22.

Dangwal, R., \& Kapur, P. (2009b). Social networking effect at “HiWEL” kiosks amongst children. Multicultural Education \& Technology Journal, 3(4), 290-305.

Dangwal, R., Sharma, K., \& Hazarika, S. (2014). Hole-in-the-wall learning stations and academic performance among rural children in India. Journal for Multicultural Education, 8(1), 31-53. 
Dangwal, R., \& Thounaojam, M. (2011). Self regulatory behaviour and minimally invasive (MIE) education: A case study in the Indian context. International Journal of Education and Development using Information and Communication Technology, 7(1), 120-140.

DeBoer, J. (2009). The relationship between environmental factors and usage behaviors at 'Hole-inthe- wall' computers. International Journal of Educational Development, 29(1), 91-98.

Elmenreich, W., \& de Meer, H. (2008). Self-organizing networked systems for technical applications: A discussion on open issues. Lecture Notes in Computer Science, 5343, 1-9.

Heisenberg, W. V. (1927). U "ber den anschaulichen Inhalt der quantentheoretischen Kinematik und Mechanik [The actual content of quantum theoretical kinematics and mechanics]. Zeitschrift fu" $r$ Physik, 43(3-4), 172-198.

Huxley, J. S., \& Huxley, T. H. (1947). Evolution and ethics: 1893-1943. London: The Pilot Press. Inamdar, P. (2004). Computer skills development by children using 'Hole in the Wall' facilities in rural India. Australasian Journal of Educational Technology, 20(3), 337-350.

Inamdar, P., \& Kulkarni, A. (2007). 'Hole-In-The-Wall' computer kiosks foster mathematics achievement: A comparative study. Educational Technology \& Society, 10(2), 170-179. Knudsen Eric I. (2004) Sensitive periods in the Development of the Brain and Behavior. Journal of Cognitive Neuroscience 16:8, pp. 1412-1425, Massachusetts Institute of Technology Kulkarni, S. \& Mitra, S. (2010). Management of Remote Mediation for Children's Education over the Internet. In Z. Abas et al. (Eds.), Proceedings of Global Learn 2010 (pp. 2044-2049). AACE.

Mitra, S. (2012). Beyond the hole in the wall: Discover the power of self-organized learning. New York: TED Books.

Mitra, S., \& Dangwal, R. (2010). Limits to self-organising systems of learning: The Kalikuppam experiment. British Journal of Educational Technology, 41(5), 672-688. 
Mitra, S., Dangwal, R., \& Thadani, L. (2008). Effects of remoteness on the quality of education: A case study from North Indian schools. Australasian Journal of Educational Technology, 24(2), 168-180.

Mitra, S., Ritu, D., Shiffon, C., Jha, S., Bisht, R. S., \& Kapur, P. (2005). Acquisition of computer literacy on shared public computers: Children and the "hole in the wall". Australasian Journal of Educational Technology, 21(3), 407-426.

Mitra, S., Tooley, J., Inamdar, P., \& Dixon, P. (2003). Improving English pronunciation: An automated instructional approach. Information Technology and International Development, 1(1), 741-783.

Shannon, C. E. (1948). A mathematical theory of communication. The Bell System Technical Journal, $27,379-423,623-656$.

Taylor, M. (2007). Battle in print: The debate over examinations is little more than a War of the Poses. Battle of Ideas. November 20.

Thomas, M. and Johnson, M. H. (2008). New Advances in Understanding Sensitive Periods in Brain Development Vol 17-No 1. Association for Psychological Science

Thomas, M. \& Knowland, V. (2009) Sensitive Periods in Brain Development - Implications for Education Policy. Touch Briefings

Winter, P. \& Ministerial Council for Education, Early Childhood Development and Youth Affairs (Australia) \& Early Childhood Services Ltd (2010). Engaging Families in the Early Childhood Development Story neuroscience and early childhood development: summary of selected literature and key messages for parenting. Ministerial Council for Education, Early Childhood Development and Youth Affairs, [Carlton South, Vic.] 